Research Article

\title{
Microstructure and Density of Sintered ZnO Ceramics Prepared by Magnetic Pulsed Compaction
}

\author{
Ji-Woon Lee $\mathbb{D}^{1},{ }^{1}$ Changhyun Jin, ${ }^{1}$ Soon-Jig Hong, ${ }^{2}$ and Soong-Keun Hyun $\mathbb{D}^{1}$ \\ ${ }^{1}$ Department of Materials Science and Engineering, Inha University, Incheon 22212, Republic of Korea \\ ${ }^{2}$ Division of Advanced Materials Engineering, Kongju National University, Kongju 32588, Republic of Korea
}

Correspondence should be addressed to Soong-Keun Hyun; skhyun@inha.ac.kr

Received 20 November 2017; Revised 5 February 2018; Accepted 19 February 2018; Published 26 March 2018

Academic Editor: Mikhael Bechelany

Copyright (c) 2018 Ji-Woon Lee et al. This is an open access article distributed under the Creative Commons Attribution License, which permits unrestricted use, distribution, and reproduction in any medium, provided the original work is properly cited.

Three different sintered $\mathrm{ZnO}$ ceramics were prepared by magnetic pulsed compaction (MPC) and other conventional methods. The microstructures of the sintered $\mathrm{ZnO}$ ceramics prepared by $\mathrm{MPC}$ at sintering temperatures ranging from 900 to $1300^{\circ} \mathrm{C}$ showed a homogeneous grain growth compared to those of the samples prepared using other methods under the same sintering conditions. This implies that interpowders and/or intergrains can induce the minimization of wall friction effect because of the application of a high compaction pressure for a short process time in the MPC method. In addition, the microstructure of the sample obtained using the cold isostatic pressing method showed the presence of heterogeneous regions, indicating its low quality even though the densities of the three different samples were almost similar in the range of 97-99\% at sintering temperatures of 900,1100 , and $1300^{\circ} \mathrm{C}$. Therefore, different methods used for the compaction of $\mathrm{ZnO}$ ceramics may result in different microstructural and physical properties of the product.

\section{Introduction}

Recently, $\mathrm{ZnO}$ has attracted increasing attention in various research areas, such as solar cells, transparent electrodes, varistors, gas sensors, and piezoelectric devices [1-4]. This is because $\mathrm{ZnO}$ exhibits high transmittance in the visible region, and its electrical resistivity can be easily controlled by doping with elements such as $\mathrm{Al}$ [5-8] and $\mathrm{Ga}$ [9-11]. $\mathrm{ZnO}$ is also advantageous from the economic and the environmental viewpoints owing to its low cost and nontoxic properties [12-14]. However, most of the recent studies are focused on low-dimensional $\mathrm{ZnO}$ nanostructures because the 0 - and 1-dimensional nanoscale is relatively free from electric and magnetic barriers, and consequently, they exhibit diverse and complicated functions when compared to the bulk materials. In other words, studies on the comparison of sintered $\mathrm{ZnO}$ bulk ceramics prepared using different synthetic methods are very scarce because of the time-consuming multimanipulations. Most importantly, the sintered $\mathrm{ZnO}$ ceramics should exhibit high relative density and microstructural homogeneity to ensure the reliability of the product. Sintered $\mathrm{ZnO}$ ceramics are generally prepared via a series of optimization processes consisting of compacting, sintering, and thin-film deposition. Among these steps, the compacting process is the most critical because the physical properties of the compact mainly determine the final optical and electrical properties of the prepared $\mathrm{ZnO}$ samples. For instance, at the first stage, if there are defects in a compact or the microstructure is not uniform, they critically affect the subsequent processes. Therefore, detailed analyses are required to synthesize high-quality compacts and to understand the effects of compacting conditions on the physical properties of the sintered $\mathrm{ZnO}$ ceramics [15-19]. In this study, three different compacting methods, namely, (1) conventional uniaxial pressing, (2) cold isostatic pressing (CIP), and (3) magnetic pulsed compaction (MPC), were used for fabricating high-quality sintered $\mathrm{ZnO}$ ceramics, and the properties of the three different samples were compared. In particular, the MPC technique is more advantageous than other methods because an extremely high pressure ( $5 \mathrm{GPa})$ can be applied to the powders within a short period of time $(\sim 500 \mu \mathrm{s})$ [20]. The physical properties of the $\mathrm{ZnO}$ ceramics, 
including green and relative densities corresponding to the functional and microstructural changes in the samples, were evaluated. The comparative results were used to establish the effect of compacting conditions on the properties of the sintered $\mathrm{ZnO}$ ceramics.

\section{Materials and Methods}

The $\mathrm{ZnO}$ raw powders (99.9\% purity) used in the three different synthetic methods were purchased from Kojundo Chemical Laboratory, Japan. The average particle size of the $\mathrm{ZnO}$ raw powder was approximately $3.285 \mu \mathrm{m}$. Polyvinyl alcohol (OCI, Korea) used as a binder for the $\mathrm{ZnO}$ powder was mixed with distilled water. Then, the mixture of the slurry binder and the $\mathrm{ZnO}$ powder was completely dried to obtain bulk $\mathrm{ZnO}$.

2.1. Compacting Methods. The three different compacting methods used for preparing the sintered $\mathrm{ZnO}$ ceramics are described as follows:

(1) In uniaxial pressing, the $\mathrm{ZnO}$ powders were pressed into a steel mold after lubricating the inside of the steel mold with a BN spray for easy detachment of the $\mathrm{ZnO}$ ceramics from the steel mold. The mold diameter was $20 \mathrm{~mm}$, and the maximum pressure used for compacting $\mathrm{ZnO}$ was $165 \mathrm{MPa}$, which was applied for $1 \mathrm{~min}$.

(2) In CIP, the $\mathrm{ZnO}$ powders were compacted under a pressure of $180 \mathrm{MPa}$ for $10 \mathrm{~min}$ after uniaxial pressing at $119 \mathrm{MPa}$ for $1 \mathrm{~min}$.

(3) In MPC, the $\mathrm{ZnO}$ powders were compacted by MPC uniaxial pressing at $800 \mathrm{MPa}$ for approximately $500 \mu \mathrm{s}$. The notable feature of the MPC method is that the applied pressure and time are much higher and shorter, respectively, than those of the uniaxial pressing and the CIP methods. Table 1 presents the details of the compacting conditions, such as mass, lubrication condition, diameter, pressure, and time used for the different methods.

2.2. Sintering. All the specimens were preheated at $400^{\circ} \mathrm{C}$ for $1 \mathrm{~h}$ in air to burn off the binder from the $\mathrm{ZnO}$ samples. Then, continuous sintering was performed at 900, 1100, and $1300^{\circ} \mathrm{C}$ for 1,2 , and $4 \mathrm{~h}$ without the use of supporting gases, respectively. The heating rate for all the samples was set at $5^{\circ} \mathrm{C} \cdot \mathrm{min}^{-1}$. After the sintering process, the samples were cooled in the furnace.

2.3. Characterization. The green densities and the relative densities of the cylindrical $\mathrm{ZnO}$ samples were calculated from the weight to volume ratio. Furthermore, while calculating the relative density, Archimedes' principle was applied using distilled water for factual accuracy. For studying the microstructural properties, all the sintered samples were gradually polished with $\mathrm{SiC}$ paper and $1 \mu \mathrm{m}$ diamond paste. Subsequently, the smooth surfaces of the
TABle 1: Compacting conditions used for uniaxial pressing (Uni), cold isostatic pressing (CIP), and magnetic pulsed compaction (MPC) processes.

\begin{tabular}{llc}
\hline $\begin{array}{l}\text { Compact mass } \\
\text { Lubrication condition }\end{array}$ & & $\begin{array}{c}11.22 \mathrm{~g} \\
\text { BN sprayed }\end{array}$ \\
\hline Mold diameter & Uni & $20 \mathrm{~mm}$ \\
\hline \multirow{2}{*}{ Compacting pressure } & MPC & $165 \mathrm{MPa}$ \\
& CIP (Uni) & $180(119) \mathrm{MPa}$ \\
& MPC & $800 \mathrm{MPa}$ \\
\hline \multirow{2}{*}{ Compacting time } & Uni & $1 \mathrm{~min}$ \\
& CIP & $10 \mathrm{~min}$ \\
& MPC & $\sim 500 \mu \mathrm{s}$ \\
\hline
\end{tabular}

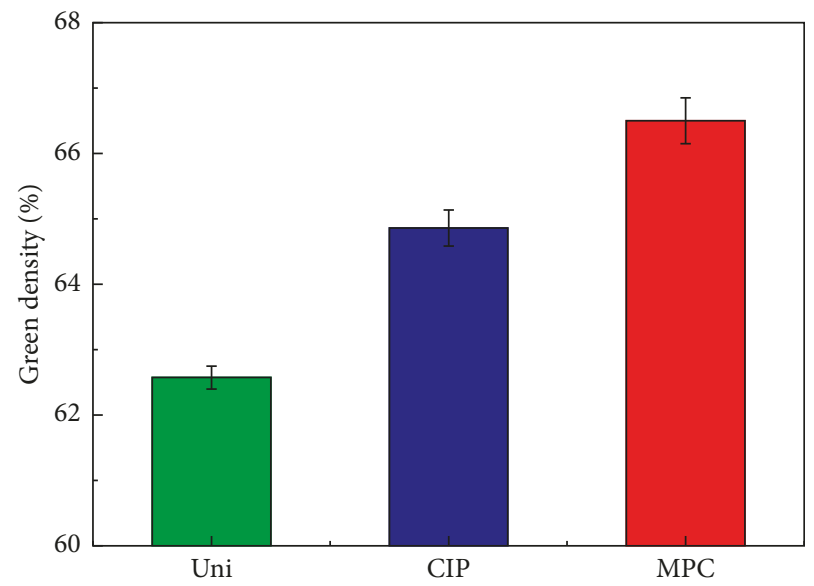

Figure 1: Variations in the green densities of the $\mathrm{ZnO}$ ceramics prepared using the three compacting methods (uniaxial pressing, CIP, and MPC) with respect to the sintering temperature and duration.

specimens were etched with hydrochloric acid for $30 \mathrm{~s}$. The microstructural observations of parallel and perpendicular cross sections were performed using a Keyence VHX-900 optical microscope and a Hitachi S-4300SE scanning electron microscope. The mean grain sizes were measured using the image analysis software.

\section{Results and Discussion}

3.1. Compacting Properties. Figure 1 shows the comparison of the green densities of the $\mathrm{ZnO}$ compacts prepared by the three compacting methods. The green densities of the samples prepared using the different methods are approximately in the range of 60 to $68 \%$. It appears that there was no significant difference in the value of green density even though the compacting pressure used in MPC was 4.8 times larger than the compacting pressure used in uniaxial pressing (Table 1). The green density of the uniaxially pressed compacts was $62.6 \%$, and that of the CIP compacts with uniaxial pressing was $64.9 \%$. The maximum green density of $66.5 \%$ was obtained using the MPC method. Based on this result, we surmise that the relationship between the 
compacting pressure and the green density is not linear. In addition, it also seems to be converging to a certain maximum value. Nevertheless, it is important to determine the best method among the three because the green density can generally affect the final relative density at the same sintering conditions [21].

3.2. Sintering Properties. The relative densities of the three different $\mathrm{ZnO}$ ceramics sintered at different temperatures and durations are shown in Figure 2. The densities of all the sintered $\mathrm{ZnO}$ ceramics increased with increase in the sintering temperature. This is correlated with the number, and the size of pores decreases as the sintering temperature increases [22]. For example, the samples compacted by the three different methods exhibited densities greater than 97, 98 , and $99 \%$, at 900,1100 , and $1300^{\circ} \mathrm{C}$, respectively. However, the relative density values of the samples compacted using the MPC method at $1300^{\circ} \mathrm{C}$ were slightly lower than those of the samples compacted using the uniaxial pressing and CIP methods. While the effect of sintering temperature on the relative density of the compacted sample is consistent, there is no direct relationship between the sintering time and the density except for samples compacted using MPC, as can be seen from Figure 2. This is in contrast to a previous report, in which the relative density of $\mathrm{ZnO}$ ceramics was found to be dependent on sintering time in the isothermal sintering test [23]. Therefore, the inconsistent results related to the sintering time observed in the present study can be associated with the nonisothermal sintering test arising from the densification and the consequent grain growth phenomena during the sintering processes.

3.3. Microstructural Properties. Figure 3 shows the variations in the grain sizes of the different sintered $\mathrm{ZnO}$ ceramics. At $900^{\circ} \mathrm{C}$, no grain growth was observed regardless of the compacting method and the sintering time. Only the densification phenomena occurred because the supplied thermal energy at $900^{\circ} \mathrm{C}$ was not sufficient for atomic diffusion from one site to the other. However, at 1100 and $1300^{\circ} \mathrm{C}$, notable grain growth occurred, and the grain size increased with increase in the temperature. The accelerating tendency of the grain growth was more evident in the samples compacted using the MPC method. In other words, the grain size of the sintered $\mathrm{ZnO}$ ceramics prepared using the MPC method was larger than that of the samples prepared using the other compacting methods at the same sintering conditions. However, Ahn et al. [24] studied the effects of green density on grain growth and reported that a high green density can suppress the grain growth during sintering. Therefore, the unusual trend in the grain growth observed in the samples prepared using the MPC method is believed to be caused by the aggregation of minute amounts of grains with sizes smaller than the critical grain size.

Figures 4 and 5 show the results of microstructural observations at the central (marked as (a)) and the outer (marked as (b)) regions of the parallel and the perpendicular cross sections of the samples prepared by CIP (Figure 4) and

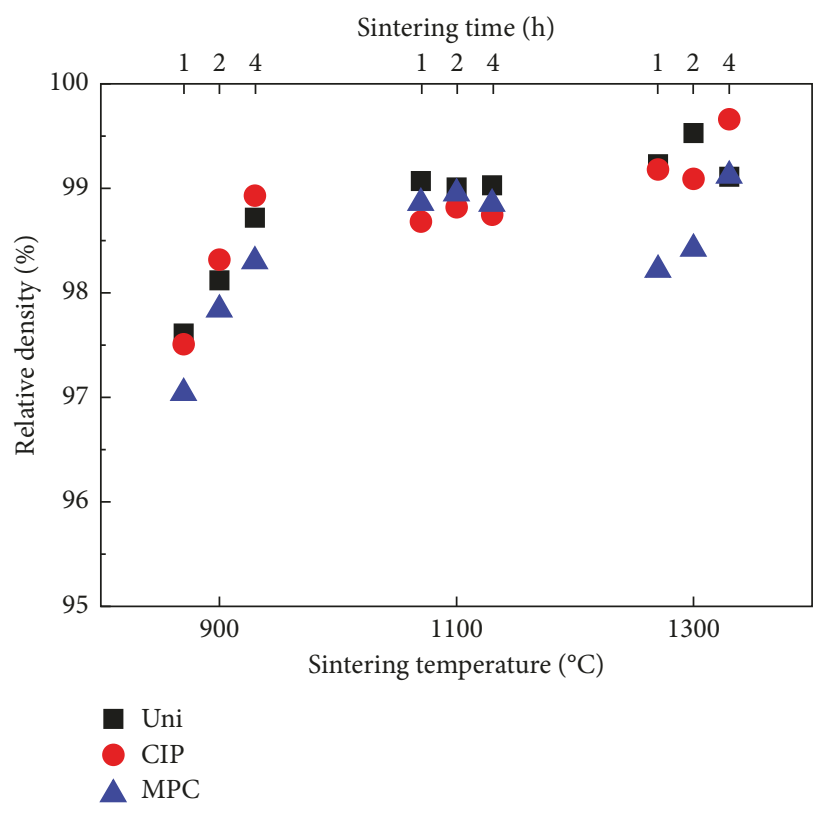

Figure 2: Variations in the relative densities of the sintered $\mathrm{ZnO}$ ceramics prepared using the three compacting methods (uniaxial pressing, CIP, and MPC) with respect to the sintering temperature and duration.

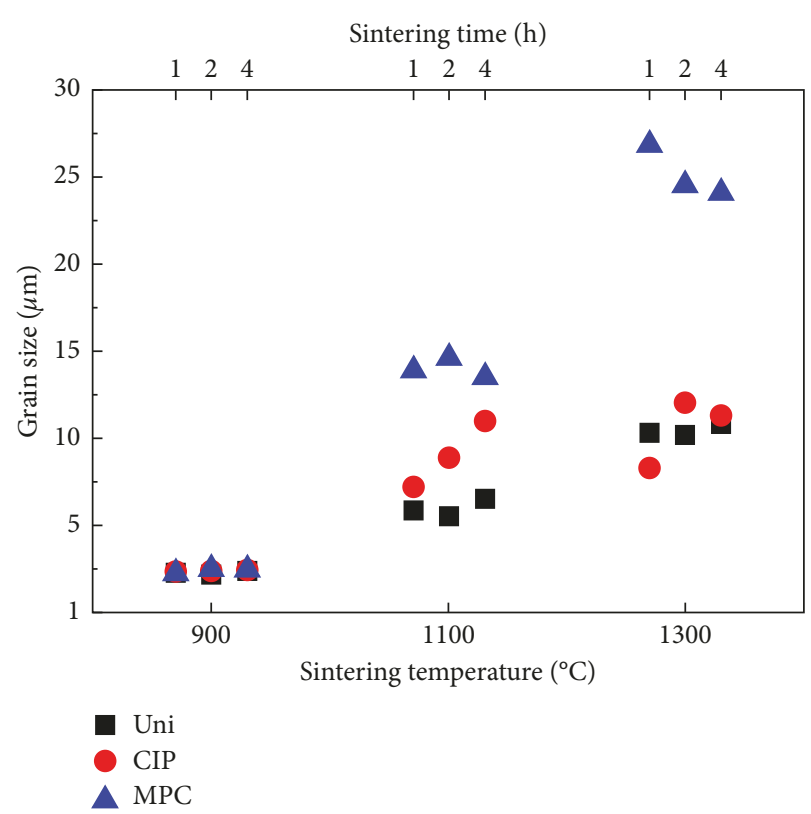

FIGURE 3: Variations in the grain sizes of the sintered $\mathrm{ZnO}$ ceramics prepared using the three compacting methods (uniaxial pressing, $\mathrm{CIP}$, and MPC) with respect to the sintering temperature and duration.

MPC (Figure 5), respectively. The sintered $\mathrm{ZnO}$ ceramics synthesized using the CIP method showed a significant difference in the grain size at the center and the outer regions irrespective of the direction of the cross section. In other words, the grain size and the density at the central region of the $\mathrm{ZnO}$ ceramics compacted using the CIP method are 


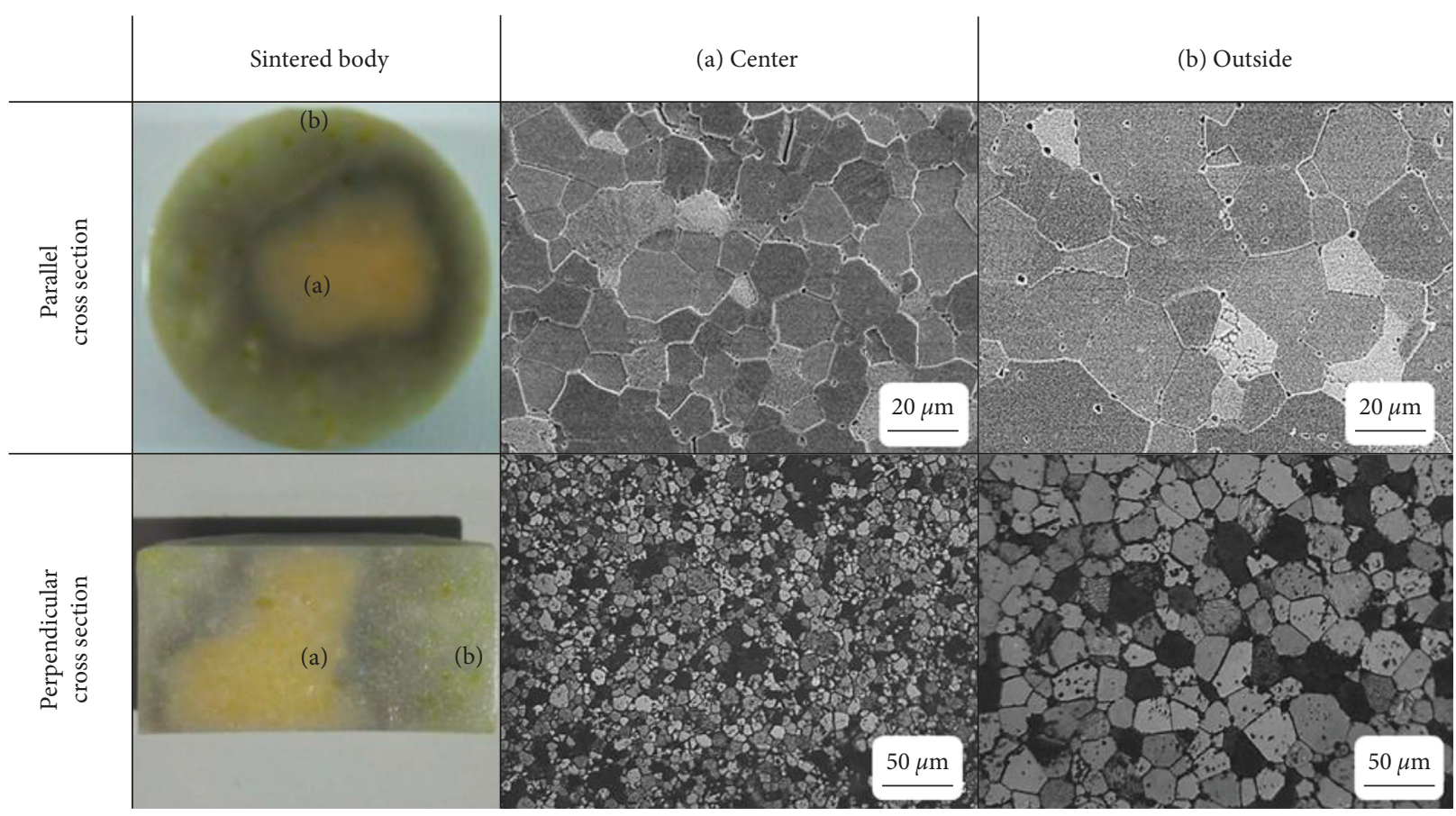

Figure 4: Perpendicular and parallel cross-sectional microstructures of the $\mathrm{ZnO}$ ceramics compacted by uniaxial pressing and CIP and sintered at $1300^{\circ} \mathrm{C}$ for $2 \mathrm{~h}$ recorded from (a) central region and (b) outer region.

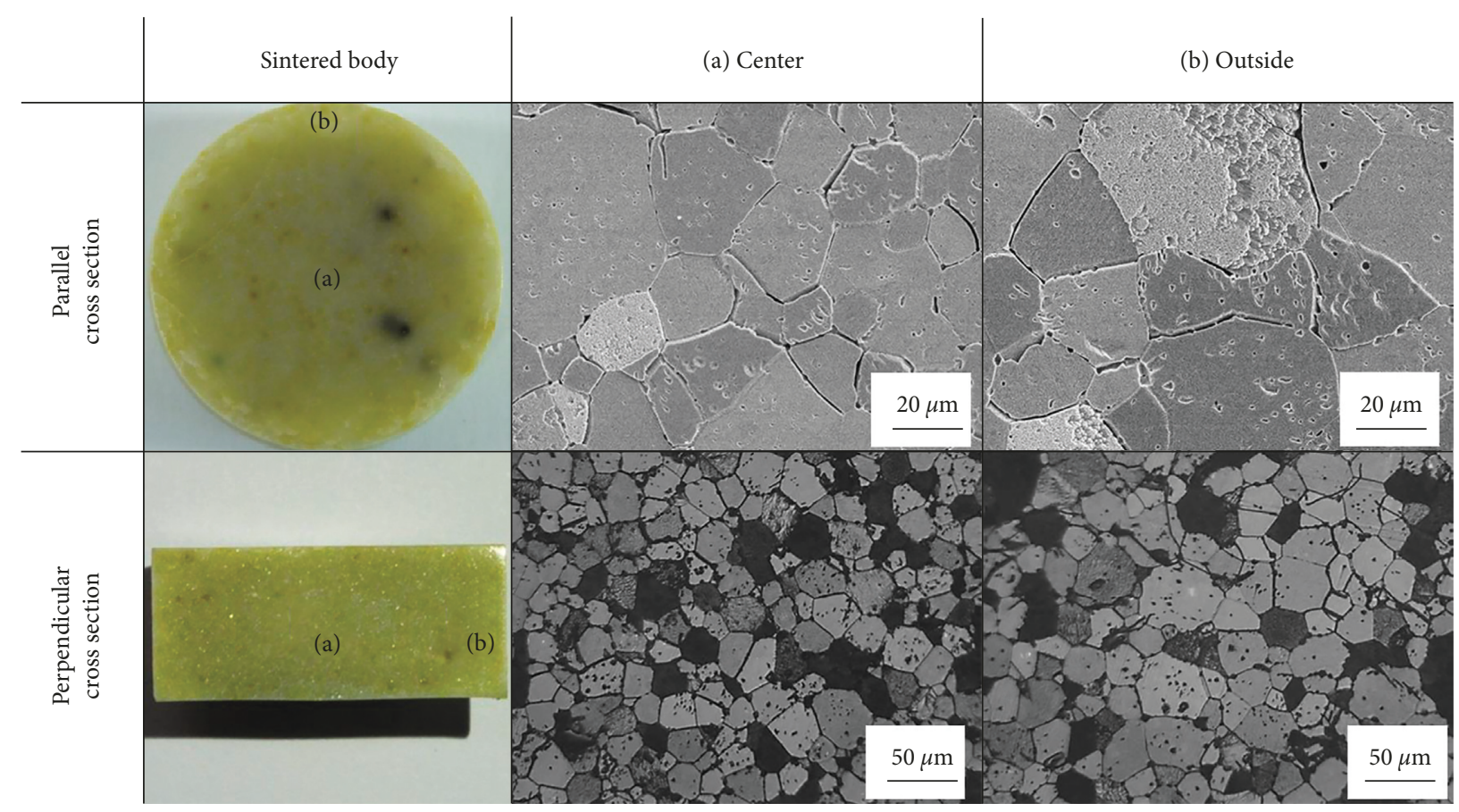

Figure 5: Perpendicular and parallel cross-sectional microstructures of the $\mathrm{ZnO}$ ceramics compacted by MPC and sintered at $1300^{\circ} \mathrm{C}$ for $2 \mathrm{~h}$ recorded from (a) central region and (b) outer region.

slightly smaller and higher, respectively, than those at the outer region (Figure 4). However, the sintered $\mathrm{ZnO}$ ceramics compacted using the MPC method showed a similar grain size and density at the central and the outer regions. This indicates increased grain growth and more homogeneous grain size distribution in the sintered $\mathrm{ZnO}$ ceramics compacted using the MPC method than the samples prepared using the other compacting methods at the same sintering conditions. The grain size distributions of all the samples are given in Table 2. 
TABLE 2: Comparison of the grain sizes of the central and outer regions in the sintered specimens prepared using the three compacting methods (uniaxial pressing, CIP, and MPC).

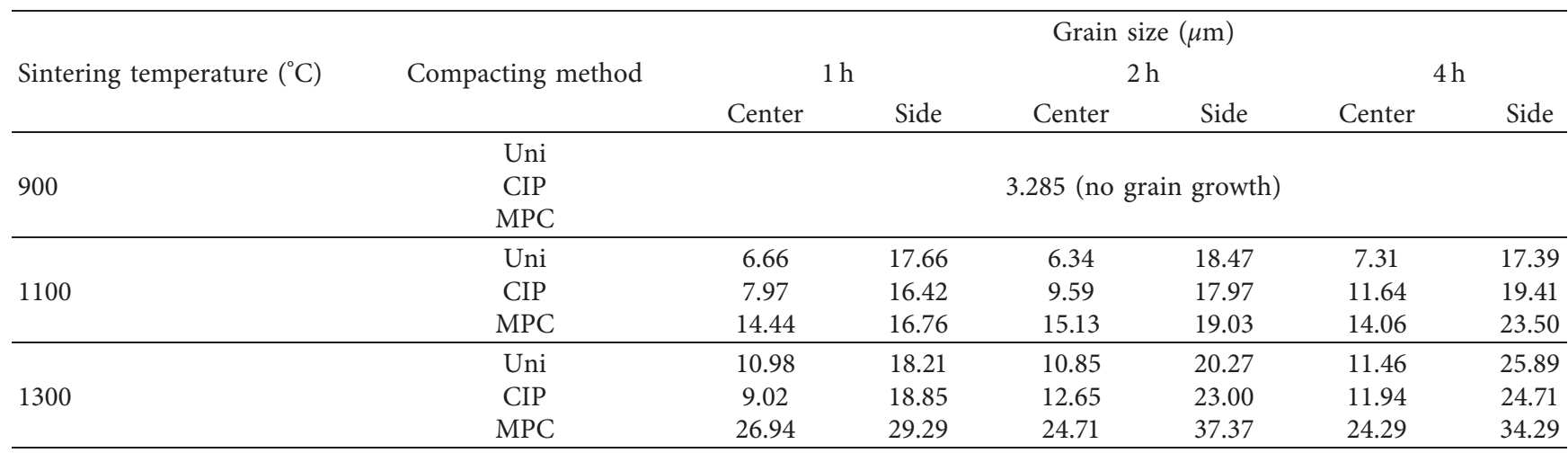

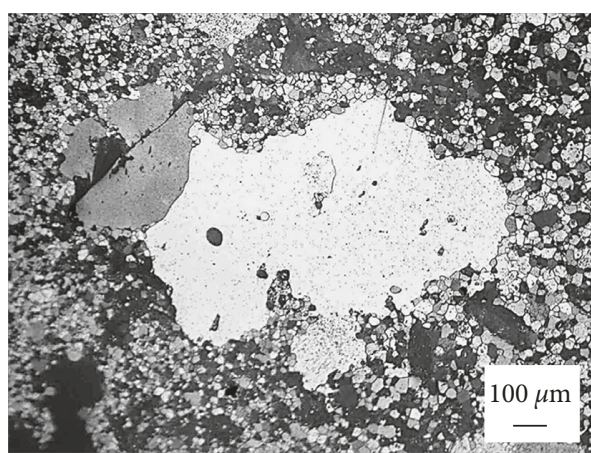

(a)

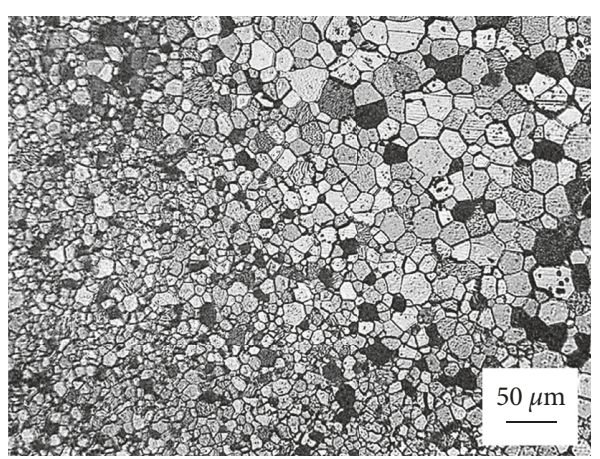

(b)

Figure 6: Perpendicular and parallel cross-sectional microstructures of the $\mathrm{ZnO}$ ceramics compacted by $\mathrm{MPC}$ and sintered at $1300^{\circ} \mathrm{C}$ for $2 \mathrm{~h}$ recorded from (a) central region and (b) outer region.

The microstructures of the sintered $\mathrm{ZnO}$ sample prepared by uniaxial pressing and CIP at $1300^{\circ} \mathrm{C}$ are presented in Figure 6. Compared with normal microstructures, two specialized regions existed: one corresponding to abnormal grain growth (Figure 6(a)) and the other corresponding to grain size transition (Figure 6(b)). The abnormal grain growth was not observed in the sintered $\mathrm{ZnO}$ ceramics prepared using the MPC method, whereas it was observed in the samples prepared by uniaxial pressing and CIP as shown in Figure 6(a). Furthermore, the grain size transition region was observed in the samples prepared by uniaxial pressing and CIP at $1300^{\circ} \mathrm{C}$, while it did not exist in the sample prepared using the MPC method (Figure 6(b)). The main cause for the abnormal grain growth and the grain size transition is probably the relative density inhomogeneity arising from the friction between the mold wall and the $\mathrm{ZnO}$ powders during the compaction process as it has been reported previously $[25,26]$.

Figure 7 shows the effect of relative density inhomogeneity on the microstructure of $\mathrm{ZnO}$ samples prepared by uniaxial pressing and CIP. The grain growth tendency at the outer region is gradually increased because of its higher relative density. On the other hand, the onset of grain growth at the center is delayed. Owing to the instability arising from the differences in the grain growth at different regions, the region of abnormal grain growth was observed only at the

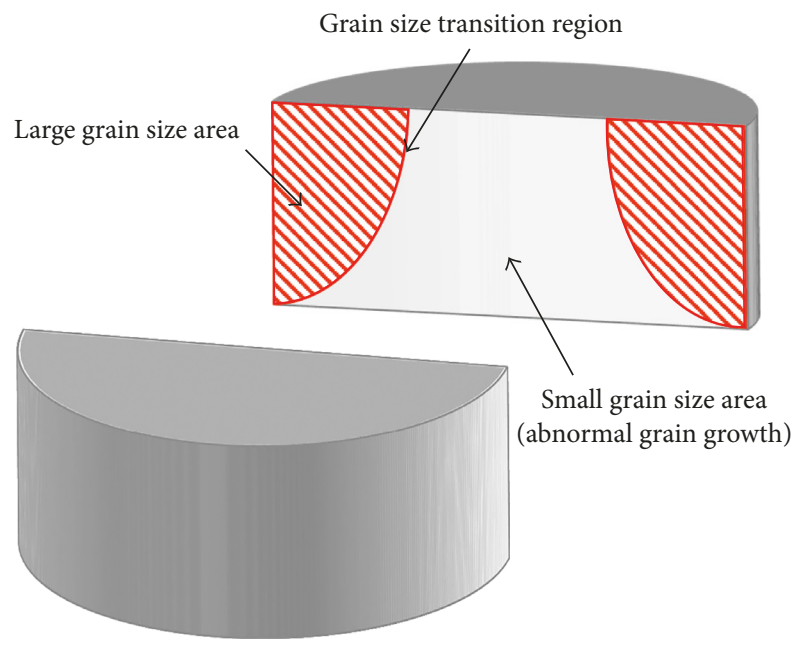

Figure 7: Schematic diagram of the sintered $\mathrm{ZnO}$ ceramic compacted by uniaxial pressing and CIP.

center. However, the grain size homogeneity observed in the MPC method is attributed to the high compacting pressure $(800 \mathrm{MPa})$ applied for an extremely short period of time $(\sim 500 \mu \mathrm{s})$. In short, the MPC method minimizes the effects of wall friction that causes nonuniformity in the grain size. 


\section{Conclusions}

In this study, pure $\mathrm{ZnO}$ ceramics were compacted by MPC, and their physical properties such as green and relative densities and the microstructure were compared with those of the $\mathrm{ZnO}$ samples compacted by uniaxial pressing and CIP. The following conclusions were drawn from the experimental results:

(1) The green density of the MPC compacts was $66.5 \%$, which is the highest value when compared to the densities of the samples prepared by uniaxial pressing (65.6\%) and CIP (64.9\%). The relative density was greater than 97, 98, and 99\%, respectively, at 900,1100 , and $1300^{\circ} \mathrm{C}$ regardless of the compacting methods.

(2) The grain growth tendency of the sintered $\mathrm{ZnO}$ ceramics increased with increase in the temperature from 1100 to $1300^{\circ} \mathrm{C}$. This is attributed to the aggregation of minute amounts of grains with sizes smaller than the critical grain size.

(3) The sintered $\mathrm{ZnO}$ ceramics compacted using the MPC method showed a homogeneous grain size at the inner and outer regions of the samples without the formation of abnormal grain growth and grain size transition regions. The MPC method can be used to achieve microstructural homogeneity because of the application of a high compacting pressure $(800 \mathrm{MPa})$ for an extremely short period of time $(\sim 500 \mu \mathrm{s})$.

\section{Conflicts of Interest}

The authors declare that there are no conflicts of interest regarding the publication of this paper.

\section{Acknowledgments}

This work was supported by The Leading Human Resource Training Program of Regional Neo Industry through the National Research Foundation of Korea (NRF) funded by the Ministry of Science, ICT and Future Planning (no. 2016H1D5A1910612).

\section{References}

[1] V. Tiron, L. Sirghi, and G. Popa, "Control of aluminium doping of $\mathrm{ZnO}$ : Al thin films obtained by high-power impulse magnetron sputtering," Thin Solid Films, vol. 520, no. 13, pp. 4305-4309, 2012.

[2] H. Kim, J. S. Horwitz, W. H. Kim, A. J. Makinen, Z. H. Kafafi, and D. B. Chrisey, "Doped $\mathrm{ZnO}$ thin films as anode materials for organic light-emitting diodes," Thin Solid Films, vol. 420421, no. 2, pp. 539-543, 2002.

[3] L. Cai, G. Jiang, C. Zhu, and D. Wang, "High quality Al-doped $\mathrm{ZnO}$ thin films deposited using targets prepared by chemical coprecipitation," Physica Status Solidi A, vol. 206, no. 7, pp. 1461-1464, 2009.

[4] N. Neves, R. Barros, E. Antunes et al., "Sintering behavior of nano- and micro-sized $\mathrm{ZnO}$ powder targets for $\mathrm{rf}$ magnetron sputtering applications," Journal of American Ceramic Society, vol. 95, no. 1, pp. 204-210, 2012.

[5] D. Xu, Z. Deng, Y. Xu et al., "An anode with aluminum doped on zinc oxide thin films for organic light emitting devices," Physics Letters A, vol. 346, no. 1-3, pp. 148-152, 2005.

[6] Y. H. Chou, J. L. H. Chau, W. L. Wang, C. S. Chen, S. H. Wang, and C. C. Yang, "Preparation and characterization of solid-state sintered aluminum-doped zinc oxide with different alumina contents," Bulletin of Materials Science, vol. 34, no. 3, pp. 477-482, 2011.

[7] C. P. Liu and G. R. Jeng, "Properties of aluminum doped zinc oxide materials and sputtering thin films," Journal of Alloys and Compounds, vol. 468, no. 1-2, pp. 343-349, 2009.

[8] J. Zhang, W. Zhang, E. Zhao, and H. J. Jacques, "Study of high-density AZO ceramic target," Materials Science in Semiconductor Processing, vol. 14, no. 3-4, pp. 189-192, 2011.

[9] H. Makino, Y. Sato, N. Yamamoto, and T. Yamamoto, "Changes in electrical and optical properties of polycrystalline Ga-doped $\mathrm{ZnO}$ thin films due to thermal desorption of zinc," Thin Solid Films, vol. 520, no. 5, pp. 1407-1410, 2011.

[10] M. Miyazaki, K. Sato, A. Mitsui, and H. Nishimura, "Properties of Ga-doped $\mathrm{ZnO}$ films," Journal of Non-Crystalline Solids, vol. 218, pp. 323-328, 1997.

[11] Y. Sato, H. Makino, N. Yamamoto, and T. Yamamoto, "Structural, electrical and moisture resistance properties of Ga-doped ZnO films," Thin Solid Films, vol. 520, no. 5, pp. 1395-1399, 2011.

[12] J. I. Nomoto, M. Konagai, K. Okada, T. Ito, T. Miyata, and T. Minami, "Modeling of phosphorus diffusion in Ge accounting for a cubic dependence of the diffusivity with the electron concentration," Thin Solid Films, vol. 518, no. 11, pp. 2937-2940, 2010.

[13] C. S. Hsi, B. Houng, B. Y. Hou, G. J. Chen, and S. L. Fu, "Effect of $\mathrm{Ru}$ addition on the properties of $\mathrm{Al}$-doped $\mathrm{ZnO}$ thin films prepared by radio frequency magnetron sputtering on polyethylene terephthalate substrate," Journal of Alloys and Compounds, vol. 464, no. 1-2, pp. 89-94, 2008.

[14] H. S. Huang, H. C. Tung, C. H. Chiu et al., "Highly conductive alumina-added $\mathrm{ZnO}$ ceramic target prepared by reduction sintering and its effects on the properties of deposited thin films by direct current magnetron sputtering," Thin Solid Films, vol. 518, no. 21, pp. 6071-6075, 2010.

[15] N. Neves, R. Barros, E. Antunes et al., "Aluminum doped zinc oxide sputtering targets obtained from nanostructured powders: processing and application," Journal of European Ceramic Society, vol. 32, no. 16, pp. 4381-4391, 2012.

[16] Y. H. Sun, W. H. Xiong, C. H. Li, and L. Yuan, "Effect of dispersant concentration on preparation of an ultrahigh density $\mathrm{ZnO}-\mathrm{Al}_{2} \mathrm{O}_{3}$ target by slip casting," Journal of the American Ceramic Society, vol. 92, no. 9, pp. 2168-2171, 2009.

[17] T. Senda and R. C. Bradt, "Grain growth in sintered $\mathrm{ZnO}$ and $\mathrm{ZnO}-\mathrm{Bi}_{2} \mathrm{O}_{3}$ ceramics," Journal of American Ceramic Society, vol. 73, no. 1, pp. 106-114, 1990.

[18] M. Mazaheri, S. A. Hassanzadeh-Tabrizi, and S. K. Sadrnezhaad, "Hot pressing of nanocrystalline zinc oxide compacts: densification and grain growth during sintering," Ceramics International, vol. 35, no. 3, pp. 991-995, 2009.

[19] X. J. Qin, G. J. Shao, R. P. Liu, and W. K. Wang, "Sintering characteristics of nanocrystalline ZnO," Journal of Maters Science, vol. 40, no. 18, pp. 4943-4946, 2005.

[20] S. J. Hong, R. Rumman, and C. K. Rhee, "Effect of magnetic pulsed compaction (MPC) on sintering behavior of materials," in Sintering of Ceramics-New Emerging Techniques, Chapter 8, InTech, Rijeka, Croatia, 2012. 
[21] M. N. Rahaman, Sintering of Ceramics, CRC Press, New York, NY, USA, 2007.

[22] J. W. Lee, J. S. Lee, M. G. Kim, and S. K. Hyun, "Fabrication of porous titanium with directional pores for biomedical applications," Materials Transactions, vol. 54, no. 2, pp. 137-142, 2013.

[23] T. K. Gupta and R. L. Coble, "Sintering of ZnO: I, densification and grain growth," Journal of American Ceramic Society, vol. 51, no. 9, pp. 521-525, 1968.

[24] J. P. Ahn, J. K. Park, and M. Y. Huh, "Effect of green density on the subsequent densification and grain growth of ultrafine $\mathrm{SnO}_{2}$ powder during isochronal sintering," Journal of American Ceramic Society, vol. 80, no. 8, pp. 2165-2167, 1997.

[25] H. M. Macleod and K. Marshall, "The determination of density distribution in ceramic compacts using autoradiography," Powder Technology, vol. 16, no. 1, pp. 107-122, 1997.

[26] B. J. Briscoe and S. L. Rough, "The effects of wall friction in powder compaction," Colloids and Surfaces A: Physicochemical and Engineering Aspects, vol. 137, no. 1-3, pp. 103-116, 1998. 


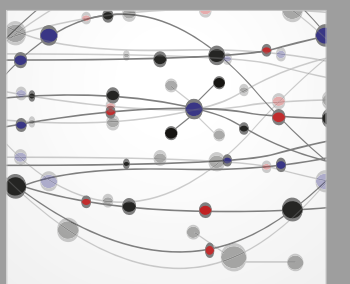

The Scientific World Journal
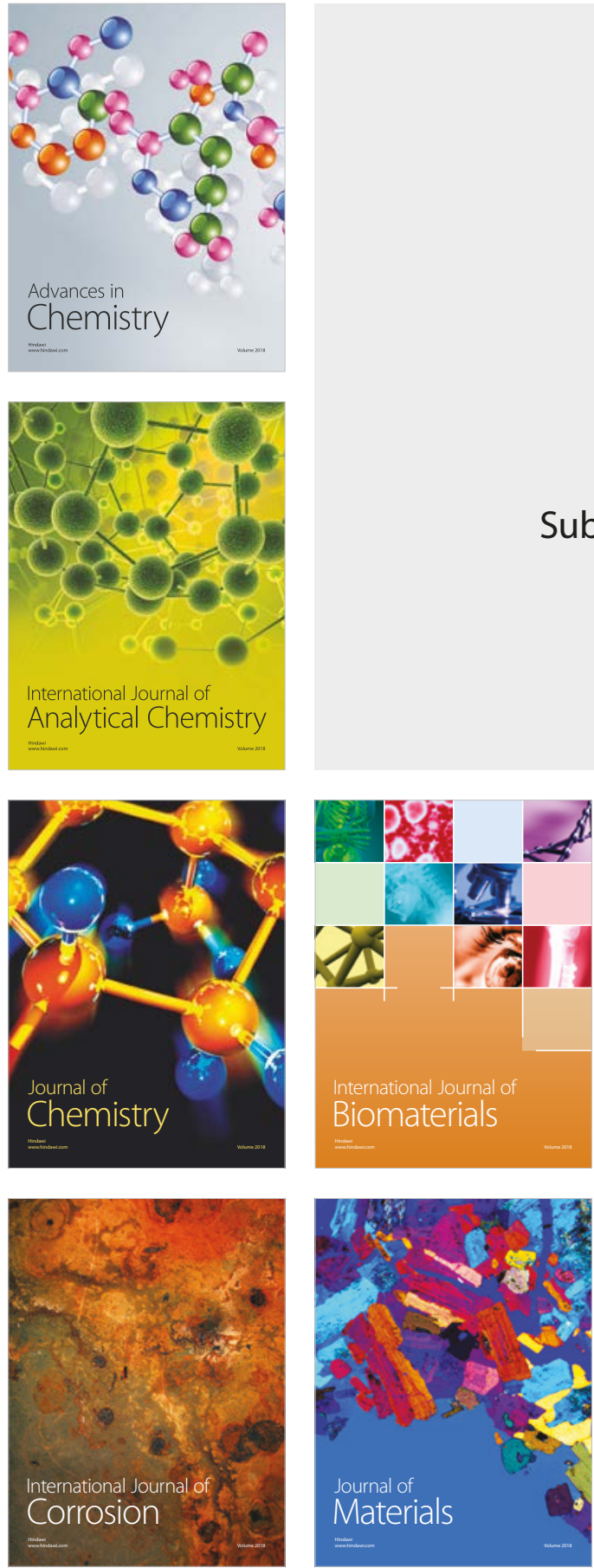

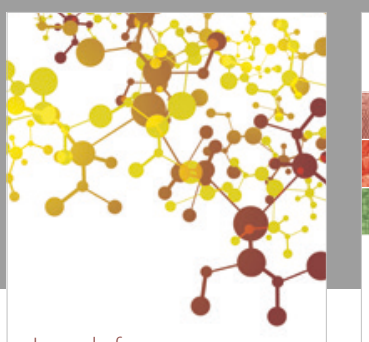

Journal of

Applied Chemistry
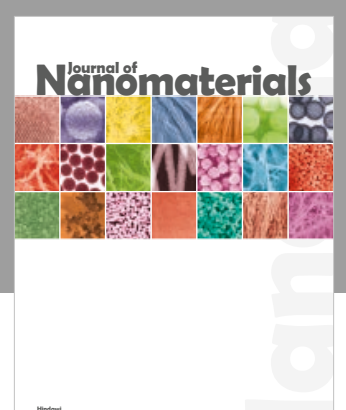

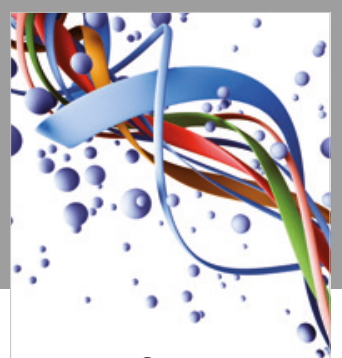

Scientifica

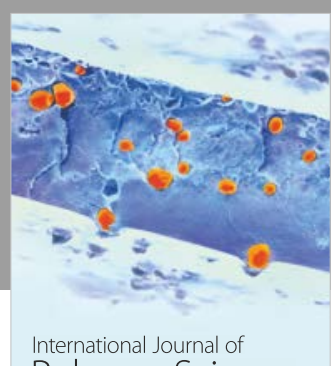

Polymer Science

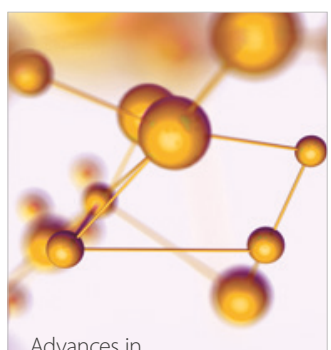

Physical Chemistry
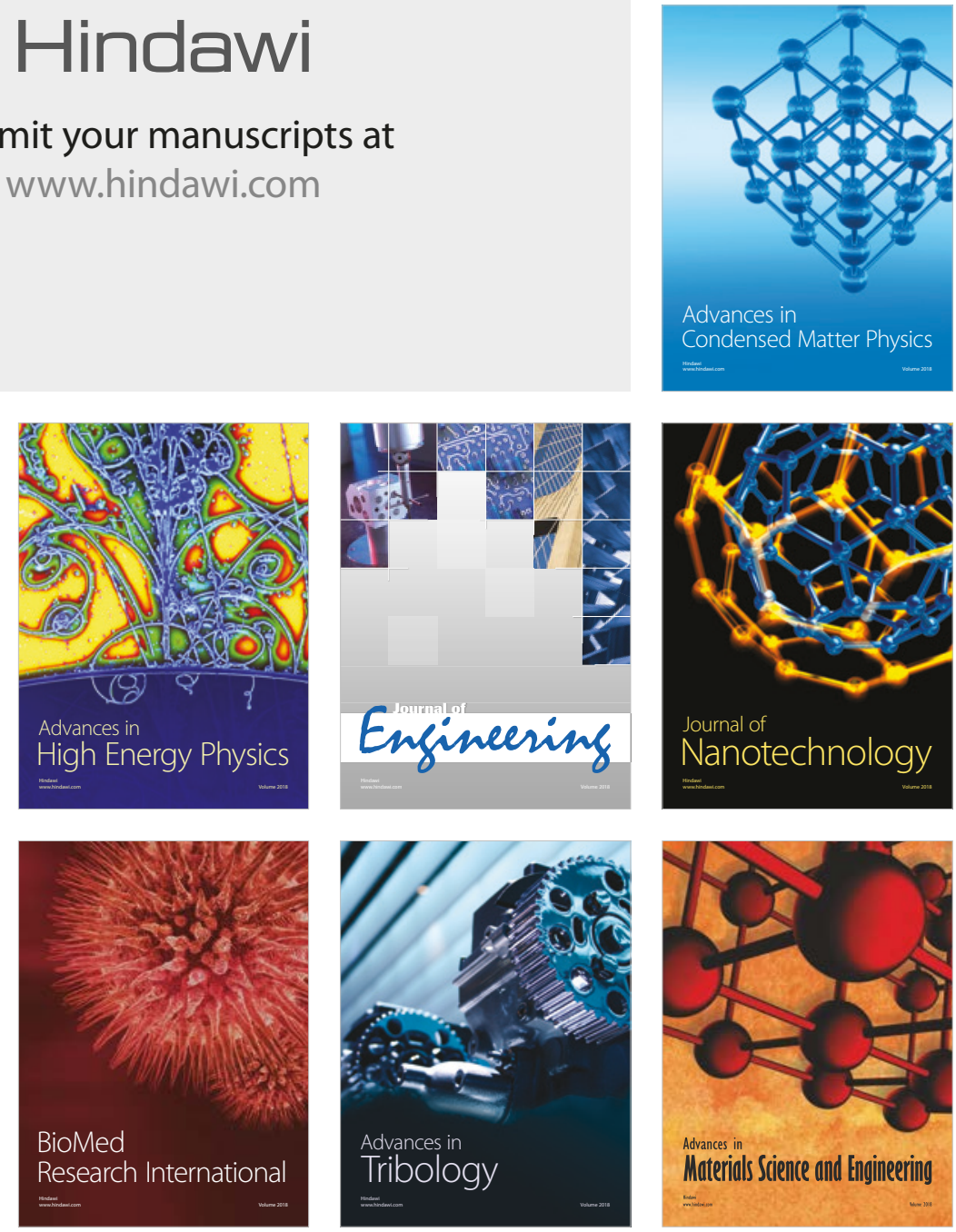